\title{
Reflexivity and transnational habitus
}

\author{
The case of a 'poor' affluent Chinese \\ international student
}

\author{
Peter I. De Costa, Magda Tigchelaar and Yaqiong Cui \\ Michigan State University / Michigan State University / Michigan State \\ University
}

Following Sayer's (2010) examination of reflexivity and habitus, we focus on the transnational habitus (Darvin \& Norton 2015) of Aaron, a Chinese international student at a U.S. university. Specifically, we examine how he wrestled with being identified as an ESL learner despite having attended a U.S. high school. Also exploring the relationship between reflexivity and emotions (Flam 2010), we draw on his written work, interviews, and his WeChat conversations. Our findings revealed that as a result of positioning himself as being better than the other Chinese students on campus (because of his English proficiency) and distancing himself from domestic U.S. students, Aaron did not capitalize on his Chinese-English bilingualism to extend his local social networks, which exacerbated his growing isolation at his home university. In tracing his emotional trajectory and strategies to cope with his predicament, we problematize the grand narrative of the global elite (Vandrick 2011) that overlooks the challenges encountered by affluent international students.

Keywords: reflexivity, transnational habitus, emotions, WeChat, identity

\section{Introduction}

According to the Institute of International Education (http://www.iie.org/), the number of Chinese students studying in the US during the 2014-2015 academic year was 304,040, constituting a 10.8 percent increase over the 2013-2014 academic year. The visible international presence of Chinese students at many U.S. universities contributes to the growing diversity in countries that have witnessed a large infusion of people, culture and capital as they crisscross both physical and cultural boundaries (Duff 2015). This evolving social landscape, which is characterized by hypersemioticization (Kramsch 2015), warrants investigation in view of the

AILA Review 29 (2016), 173-198. DoI 10.1075/aila.29.07dec

ISSN 1461-0213 / E-ISSN 1570-5595 (C) John Benjamins Publishing Company

This is an open access article licensed under the Creative Common Attribution 4.o License (CC BY-NC 4.0). 
larger commitment of applied linguistics to better understand practical everyday problems associated with language and communication. It is against this backdrop that our paper is situated as we focus on a Chinese international student, Aaron, who inhabited a transational habitus (Darvin \& Norton 2015) as he negotiated his first year at university. Using reflexivity as interpreted by Archer $(2007,2012)$ as the primary lens to guide our paper, we examine (a) how Aaron was able to reflexively use language and his personal awareness to navigate his university experience, and (b) the emotional challenges encountered by affluent international students like him. The paper closes with a discussion of some conceptual and methodological implications for future research on international university students.

\section{Reflexivity}

Drawing on sociological research, Archer (2012) defines reflexivity as "the regular exercise of the mental ability, shared by all normal people, to consider themselves in relation to their (social) contexts and vice versa" (p. 1). Put differently, reflexivity is viewed as socially conditioned self-awareness through which the individual determines her course of action in relation to the social circumstances. Extending this perspective on reflexivity to participants involved in applied linguistics projects affords a useful lens to studying the interrelationships between language, communication, culture and society, especially when Archer's (2007) reflexive modes (see Table 1) are taken into consideration. ${ }^{1}$

Table 1. Reflexive modes (Archer 2007, p. 93)

Communicative reflexives

Meta-reflexives

Fractured reflexives
Those whose internal conversations require completion and confirmation by others before resulting in courses of action. Those who are critically reflexive about their own internal conversations and critical about effective action in society. Those whose internal conversations intensify their distress and disorientation rather than leading to purposeful courses of action.

While a helpful heuristic in exploring the interplay between social conditioning and agential responses, the three reflexive modes suggested by Archer underestimate the influence of structural forces that impact the individual subject, who is constructed as a self-identity disembedded from established habits, routines, expectations and beliefs. This agency/structure divide, we argue, can be overcome

1. Archer (2007) identifies four modes: autonomous, communicative, meta- , and fractured reflexives. However, we only focus on the latter three forms of reflexivity in this paper. 
by adopting a linguistic perspective of reflexivity, that is, one which views (a) language as performance, and (b) reflexivity as being carried out through genred semiotic and discursive practices (see Pérez-Milans 2016). In embracing such a metapragmatic perspective, we align ourselves with Agha (2007: 8) who postulates that "reflexive operations can fractionally transform a norm ... through further semiotic activity ... [and enhance] the capacity of language users to acquire a reflexive grasp of particular aspects of a semiotic norm". Put differently, in this paper we focus on an individual's ability to both engage in internal conversations and enact socially mediated reflexive operations through his interactions with others. However, in highlighting the individual's reflexivity, cultural conditions such as the individual's habitus is underexplored, which in turn has created a need to revisit the concept of habitus in the era of transnationalism.

\section{Reflexivity and transnational habitus}

As part of his reflexive brand of sociology, Bourdieu (1984) put forward the construct of habitus, which he described as dispositions that are both shaped by past events and structures, and that shape current practices and structures. To him, an individual's habitus, while durable, is not cast in stone, and this stance has been instantiated in a body of applied linguistics research (e.g., De Costa 2010; Kramsch 2015) that has shown that the habitus of learners can be transformed through effort. ${ }^{2}$ Underlining the possibility of changing one's habitus, Kramsch (2015: 463) writes:

Reading Bourdieu in French, I did not ... find his theory of the social world 'deterministic' ... Bourdieu ... always insisted that our habitus has the agency to act in ways that will procure its happiness, as it interacts with the various fields it both structures and is structured by.

Recasting habitus in the age of transnationalism, Darvin and Norton (2015) recently put forward the notion of a transnational habitus - a concept that originated from urban geography (Kelly \& Lusis 2006) and migration studies (Nedelcu 2012) - in applied linguistics to account for the habitus and levels of capital enjoyed by highly mobile individuals who move across virtual and physical space and time. Their contemporary conceptualization of habitus is especially relevant in light of the revived interest in social class (e.g., Block 2015) and emotions (e.g., De Costa $2015,2016)$ in applied linguistics research that increasingly also emphasizes the

2. According to Archer (2012), however, Bourdieu's notions of habitus and cultural capital are not suitable for providing accounts of the ways in which youth navigate the social order today. 
embodied historicity of individuals. In light of this contemporary social reality, we need to combine an analysis of habitus and reflexivity - a stance that is also advocated by Adams (2006) and Sayer (2010) - to make sense of how highly mobile individuals such as affluent international students navigate transnational contexts.

Having established the significance of exploring an individual's reflexivity in conjunction with his transnational habitus, it is equally important to examine how these two constructs are enacted through discursive meaning-making practices. Such an examination, as noted earlier, bears particular relevance in a world characterized by translanguaging (Garcia \& Li 2014) and translingual practices (Canagarajah 2013), and where digital media, in particular, open up a staggering range of possibilities. More often than not, these ensembled modes of communication take the form of conventionalized norms that are artfully manipulated to yield significant effects that reveal something about the actors' identity. In that respect, these social actors are highly agentive in that they are able to create a diverse range of social-semiotic configurations as they mediate their own identities and engage in acts of impression management. However, as Jones and Hafner (2012:154) remind us, there are limits to such impression management:

While we have control over what we want to reveal and what we want to conceal, we do not have control over what other people reveal about us or the kinds of comments they make about our information.

Articulating a similar point, and viewing language and communication as a sociolinguistic system that operates through complex semiotic units, Blommaert (2015) adds that meaning is not linear but can yield several different effects. Thus taking these considerations - the transnational habitus of international students as they navigate a digitally saturated world - we posit that reflexivity can serve as a means to better understand the dilemmas of international university students in relation to wider social, cultural and economic changes. It is to this university context in which this study is situated that we turn next.

\section{The study}

This study draws on a larger longitudinal case study of Chinese international students' experiences during their first year at Great Lakes University (GLU), with a particular focus on Chinese students' language and academic socialization processes. This population had received increasing attention from administrators and instructors alike, in part because GLU had witnessed a $78.9 \%$ increase in admissions from 2408 students in Fall 2010 to 4383 in Fall 2014, which was when our study was conducted. 
The explosion in the number of Chinese students attending the university where we conducted our study is not unique to our research site. A similar phenomenon has also emerged in universities in other English-dominant countries such as Australia, Canada, England, and New Zealand, resulting in a host of attendant social and learning problems (Li \& Zhu 2013). In particular, the transition experience of Chinese undergraduate students may not always be smooth. ${ }^{3}$ Generally, these students have limited exposure to English, even though they are in a setting where English is supposedly dominant (e.g., Ranta \& Meckelborg 2013). For example, in their study of 17 students from China, Ranta and Meckelberg (2013) found that their participants only spoke English an average of 11 minutes a day in their first six months in Canada, even though they were 'immersed' in an English-dominant setting.

In light of this sociolinguistic reality and highlighting how an individual's present and past interactions shaped his or her identity and emotions, we carried out a multiple case study that focused on three Chinese students in three different situations during their first year of study at GLU: one student who had participated in a preparatory English summer course (Preparation for Academic Learning, PAL) before entering his undergraduate classes, a second student who was provisionally accepted and took classes at the English Language Institute (ELI) before he would matriculate, and a third student who was accepted for direct matriculation. All three of the students had been admitted for study in the College of Business. In this paper, we focus on the second student, Aaron, and tracked his experience both inside and outside an English as a Second Language (ESL) reading and writing class in the Fall of 2014.

\section{Focal learner: Aaron}

Aaron had been recruited by an ELI administrator, who identified him as a student who would be interested in participating in the project. The administrator also facilitated contact between the research team and the instructor of the reading and writing class, who volunteered to open her class for observation and to participate in interviews and email communication.

Aaron first came to the US midway through his sophomore year of high school and enrolled at a boarding school in Pittsburgh, Pennsylvania where he received his high school diploma. Here he developed a very close bond with a group of

3. One may argue that wider social problems facing Chinese students in Western universities is a bit overgeneralized and that Chinese students translanguage in English when interacting with other Chinese students. This sociolinguistic reality does not detract from the problem of isolation that we address in this paper. 
Chinese friends. He found that friendships with domestic students were difficult to make because while his American peers initially seemed very friendly and curious to get to know him, in subsequent exchanges they had few, superficial words for him. He also found that he did not share a similar sense of humor with the domestic students he interacted with, as they often laughed about things that he did not find funny. Aaron's decision to study at a U.S. university was in part motivated by the prospect of returning to the same country as his Chinese high school friends, who were also studying at U.S. universities.

Aaron's linguistic practices are not unlike those reported in Myles and Cheng (2003), who found that international students tend to interact with students who share a similar cultural and linguistic background to them in their academic settings. He was in regular contact with other Chinese friends in other U.S. cities by way of social media, and reported that they remained important friends. Though he almost exclusively associated with other Chinese students both in his classes and extracurricularly, these acquaintances were not meaningful to him, and he struggled to establish strong interpersonal connections in his new academic setting at GLU.

\section{Researchers}

The research team, led by Peter, also included Magda and Yaqiong, who were the field researchers in this study. Being former and current international graduate students, all three members of our team shared a commonality with Aaron in that we understood what it was like to be a non-U.S. resident university student, albeit to different degrees of understanding. ${ }^{4}$ Interestingly, however, this commonality rarely came out during Magda's interactions with Aaron, partly due to the fact that her identity as a Canadian international student who was married to a U.S. citizen was not marked by a difference in first language, or even accent. By contrast, Aaron could easily be identified as an international student when he spoke.

On the other hand, Yaqiong appeared to have more in common with Aaron, given that she had grown up in Northeastern China and went to high school and college in Shanghai before moving to Beijing. Being a native speaker of Chinese and having lived abroad in the US for several years may have helped Yaqiong better understand Aaron's situation. For example, she could empathize with his longing for American friends and his feeling of isolation and loneliness. She also served as a language broker during the interviews when Aaron needed help with translation.

4. Peter, a faculty member, is originally from Singapore, while Magda and Yaqiong, who are doctoral students, are originally from Canada and China, respectively. 
Hence, in spite of efforts to position ourselves as a friend and resource (Sarangi \& Candlin 2003), we were distinctly aware that there were limits to our level of access when it came to being able to reach out fully to Aaron. For one, all three of us were also much older than Aaron, who was 19 at the time of the study. In that respect, we do not claim to have had access to the inner workings of Aaron's mind. This realization did not stop us, however, from attempting to provide a "thick description" (Geertz 1973) of Aaron's academic socialization experience. At the same time, and recognizing that our interviews with Aaron were themselves complex social practices (Talmy 2010), which yielded valuable insights into how Aaron reflexively constructed stances, linguistic practices and trajectories in accordance with his own elite aspirations. Put simply, we acknowledge that what he said during our interviews and his online posts were filtered through his own lens, as he reflexively crafted ways to position himself to both us and his reading audiences.

\section{Findings}

To gain a holistic understanding of this experience, we collected multiple data sources (see Table 2), which included interviews with him and his female ESL instructor, email communication with her, classroom observations, artifacts of his written work, and WeChat (http://www.wechat.com/en/) posts ${ }^{5}$ All three researchers became subscribers to WeChat, which served as Magda's main mode of communication with Aaron for setting up interview meetings ${ }^{6}$ Over the course of the 2014-2015 academic year, we performed a thematic analysis of the various data sets described above. Using an iterative approach, the data were mined for indications of how Aaron's reflexivity and habitus may have impacted his academic socialization experience and ultimately his English language development.

We report our findings in relation to Archer's (2007) three reflexive modes communicative, meta-, and fractured reflexivity - introduced earlier (Table 1). In doing so, we problematize each of these modes and also examine how reflexivity was enacted from a metapragmatic perspective. Specifically, we draw on three genres - interviews, written essays and WeChat posts - in which Aaron engaged. With regard to all three genres, we take the view that reflexivity is carried out through genred semiotic and discursive practices. Also significant to note is how

5. WeChat is a free messaging and calling app that had originally been developed for users in mainland China but is used internationally now, following the creation of an English version.

6. All interviews with Aaron were led by Magda, a non-Chinese speaker, and took place primarily in English. Yaqiong, a native speaker of Chinese, was also present at these interviews. When the need emerged, Yaqiong stepped in to assist with translation. 
Table 2. Data sources

\begin{tabular}{|c|c|c|}
\hline Methods & $\begin{array}{l}\text { Collection Period: September- } \\
\text { December, } 2014\end{array}$ & Data \\
\hline Artifacts & Across the semester & $\begin{array}{l}\text { Course syllabus, assignment procedure } \\
\text { Student's written work }\end{array}$ \\
\hline \multirow[t]{2}{*}{ Interviews } & $\begin{array}{l}\text { Student interviews ( } 3 \text { interviews; } \\
\text { conducted across the semester) }\end{array}$ & Audio-recorded, 3 x 35min \\
\hline & $\begin{array}{l}\text { Instructor interview ( } 1 \text { in the } \\
\text { middle of the semester) }\end{array}$ & Audio-Recorded, 1 x 30min \\
\hline $\begin{array}{l}\text { Electronic } \\
\text { communication }\end{array}$ & Across the semester & $\begin{array}{l}11 \text { emails from instructor } \\
29 \text { WeChat moments from student }\end{array}$ \\
\hline Observations & $\begin{array}{l}2 \text { observations of Reading and } \\
\text { Writing class }\end{array}$ & Field notes \\
\hline
\end{tabular}

our consideration of transnational habitus is also woven into our analyses below. Collectively, these constructs elucidated our understanding of how Aaron grappled with the challenges associated with being an affluent international student.

Limited capital accumulation and transnational habitus enactment

Aaron came from a wealthy Chinese family, and his parents, who owned several businesses, were able to send him to a private Catholic boarding school in Pittsburgh for his earlier education. While he did not drive at GLU, Aaron had a regular taxi driver pick him up every day to ferry him to and from class. As mentioned, Aaron was waiting to get into the College of Business, with plans to move into a career in finance as evidenced in the extract below.

Extract 1. A future in finance

Magda: So the last question is again in the future. If you could have any job, your dream job, what would it be?

Aaron: Dream job. I think it's about finance.

Magda: And where would you have your job? If you could choose any city in the whole world?

Aaron: Shanghai.

Magda: What kind of accomplishments would you like to achieve? What would you like to do while you're working in finance?

Aaron: Money.

(Interview 2, November 13, 2014)

As illustrated, Aaron had no plans to live in the US in the long term. Simply put, he was not invested (Norton 2013) in building a life in this country but sought 
to return to China and find a job in Shanghai upon graduation. If anything, our semester-long interactions with him revealed that he had little desire to develop American values but wanted to preserve his Chinese identity. Admittedly, his language use is sparse here - he merely uttered few words such as 'finance,' 'Shanghai' and 'money'. However, Aaron used English reflexively to discursively position himself as a finance expert and a member of an imagined community (Anderson 1983) that was neither embedded in the US nor the small university town where he was studying. Rather, he elected to index an affluent identity as a Shanghaibased financier.

In some ways, his time in the US seemed like a sojourn that involved multiple trips throughout the US, especially to cities on the east and west coasts, where his former Pittsburgh high school friends from China were attending school. Holidays such as Thanksgiving were often spent jetting off to these cities in order to catch up with his friends.

Extract 2. Travel

Magda: Are you doing anything over the Thanksgiving break?

Aaron: Yeah.

Magda: What are you doing?

Aaron: Go to the NYC. ${ }^{7}$

Magda: Who are you going with?

Aaron: My friend in the Pitt. In Pittsburgh.

(Interview 2, November 13, 2014)

In another interview conversation, Aaron revealed that his trips to New York regularly revolved around shopping and fine dining. Specifically, his friends and he targeted Michelin-rated restaurants. In that respect, Aaron encapsulated the bodily hexis (Bourdieu 1984), that is, the expression of all the factors that make up one's habitus, associated with affluence. In other words, through the interviews, Aaron was displaying an affiliation with an elite community, and was thus indexing an identity that extended beyond a linguistic enactment to include a disposition and different ways of behaving that were associated with being a member of an affluent social class and one who appropriated a transnational habitus (Darvin \& Norton 2015).

Thus, on the surface, Aaron seemed to be one of the global elite youth that Vandrick (2011) writes about. In material terms, he could afford almost anything that money could buy, prompting a comparison to Sayer's (2010:109) observation that "children brought up in a high income, high status family are likely to gain a sense of security, ease and entitlement". Indeed, because of his economic

7. $\mathrm{NYC}=$ New York city 
capital, Aaron did bear some resemblance to the high income and status children described above. However, he was denied access to the cultural capital (Bourdieu 1984) with which one would generally associate children of affluence. This was partly because having been sent away to boarding school in the US at a young age, he was shortchanged of the opportunity to interact with professionals and managers like his parents. ${ }^{8}$

\section{Communicative and meta-reflexives: Attempted escapes from the ELI orbit}

While communicative reflexives encompass internal conversations that require completion and confirmation by others before resulting in courses of action, meta-reflexives describe individuals who are aware of their own internal conversations and critical about effective action in society (Archer 2007). Aaron was distinctly aware that his current predicament of being an ESL student was attributed to his failing the English proficiency test administered by the English Language Institute at GLU. Because of this, he was unable to matriculate as a full GLU student and had to take additional ESL classes. Having studied English for over 12 years - first in China and then as a student in Pittsburgh - Aaron was resentful that he was clustered with the international students, especially Chinese peers who had never studied in the US, and whom he thought to be his inferiors. In other words, the English he acquired from years of instruction in China and his U.S. high school were not valued at GLU, suggesting that his communicative reflexivity (Archer 2007) was in play because Aaron's resentment towards his situation was socially constructed and completed by his US peers and teachers. This in turn resulted in a course of action that entailed distancing himself from his Chinese international student peers as a mark of social distinction (Bourdieu 1984).

Crucially, this inequality of not having one's communicative repertoire legitimated is captured in Blommaert's (2005) observation, "Whenever discourses travel across the globe, what is carried with them is their shape, but their value, meaning, or function do not often travel along" (p. 72). Consequently, Aaron found his ESL classes boring, a phenomenon that was compounded by the little value he saw in learning English.

8. Aaron had an estranged relationship with his parents; he only saw them in the summer, when we went back to China for his summer break, and even then he barely communicated with them. Interpreting this lack of communication as a sign that they did not care for him, Aaron had hidden from them the truth that he was not a matriculated student at GLU but an ESL student, who was hoping to pass the language proficiency requirements in order to qualify for matriculated status. 
Extract 3. Non-valuable English

Magda: Okay, so I wanted to, another question is, do you, in the future, do you picture yourself living in the USA or China?

Aaron: China.

Magda Do you think you'll use English in China?

Aaron: No.

Magda No? You won't need it?

Aaron I don't need.

(Interview 2, November 13, 2014)

In positioning himself as someone who did not need English, and thus exercising what Archer (2007) describes as level of meta-reflexivity (i.e., being aware of an internal conversation and critical about ineffective action in society), Aaron appeared to create a separate linguistic market (Bourdieu 1991), where Chinese and not English was valued, for himself. Such a reflexive understanding of English illustrates his attempt to manipulate his transnational habitus so that it could be (re)valued in a different market, that is, one situated within the world of finance in Shanghai. Equally important to note is how Aaron uses English sparingly in Excerpt 3. On the one hand, his brief responses may evidence his level of English proficiency. On the other hand, Aaron's replies to Magda's questions may also be interpreted as a critical response - an act of linguistic resistance and hence an indication of his meta-reflexivity - at having been marginalized within an English-dominant setting.

Furthermore, his lack of investment in learning English led him to view his time at the English Language Institute (ELI) as a form of internment, one from which he sought to escape, as evidenced in the next extract. ${ }^{9}$

Extract 4. Escaping the ELI

Magda Which test is tomorrow?

Aaron ELI test.

Magda Oh, is that like a level 3 test?

Aaron: It's like, you take a test and it, maybe you did very good, you can jump the level and escape the ELI.

(Interview 3, December 4, 2014)

Aaron's apparent resentment towards the gatekeeping function of the ELI test thus becomes evident in this excerpt as he equates the passing of the test to gaining freedom. His fascinating choice of words ('jump' and 'escape') further illustrate that Aaron was communicatively- and meta-reflexively aware of the language learning

9. GLU's proficiency test was used to place students at a level of study at the ELI and to determine whether a student meets the university's basic English language requirement. 
constraints placed upon him - constraints from which he creatively sought to liberate himself. His desire to escape the routines placed upon him is also exemplified in an attempted circumvention of the multi-draft, process writing approach in his ESL class.

\section{Reflexive grasp of semiotic norms}

The next three excerpts demonstrate how Aaron attempted to "acquire a reflexive grasp of particular aspects of a semiotic norm" (Agha 2007: 8), which in this case turned out to be semiotic norms associated with the genre of academic writing, in order to graduate from the ELI. Aaron did not participate in the prewriting, planning or peer review stages of the process; he opted only to produce a draft for comments from his ESL instructor, Gail, and a final, revised draft. This is illustrated by the grades he received for each stage in the process, which are detailed in the email communications between Gail and Magda.

Extract 5. Skipping writing draft stages

[T]his is everything he [Aaron] turned in with the final draft, but it doesn't look like he turned in his brainstorming or rubric from the 2nd draft. He also doesn't have the peer review sheet because he happened to miss that day. Normally there's a lot more to the process than this because students write on each other's papers and fill out sheets during peer review. I go over their brainstorming/outline and thesis early on in the process, and I give feedback on the draft, while taking into account what they may have changed after peer review.

- brainstorming/thesis: 0/5 (he never turned it in)

- peer review: 0/10 (he wasn't there for it)

(Email 10, November 5, 2014)

In this excerpt, Gail highlights Aaron's academic shortcomings in terms of what he failed to do: he neither turned in his brainstorming and rubric nor his peer review sheet. Failure to submit these documents resulted in Aaron receiving nil scores for both of these mini assignments. In electing to not submit the assignments, Aaron essentially passed up an opportunity to demonstrate his ability to grasp the semiotic norms associated with academic writing, which consequently led to Gail's implicit assessment of him as non-diligent student.

Even though Aaron skipped the brainstorming stage, an analysis of the notes on his second draft and the revisions he made to produce the final product show that he may have gone back to do some planning after the drafting phase. As Gail pointed out (Email 11, November 11, 2014), the draft that he submitted for teacher comments did not meet the two-page length requirement (another shortcoming on 
Aaron's part). However, after receiving these comments, Aaron included an outline of some new ideas that appear for the first time in his final draft (Figure 1), where he translanguages (Garcia \& Li 2014) between Chinese and English to make meaning out of his assigned topic and elaborates on factors behind an individual's success.

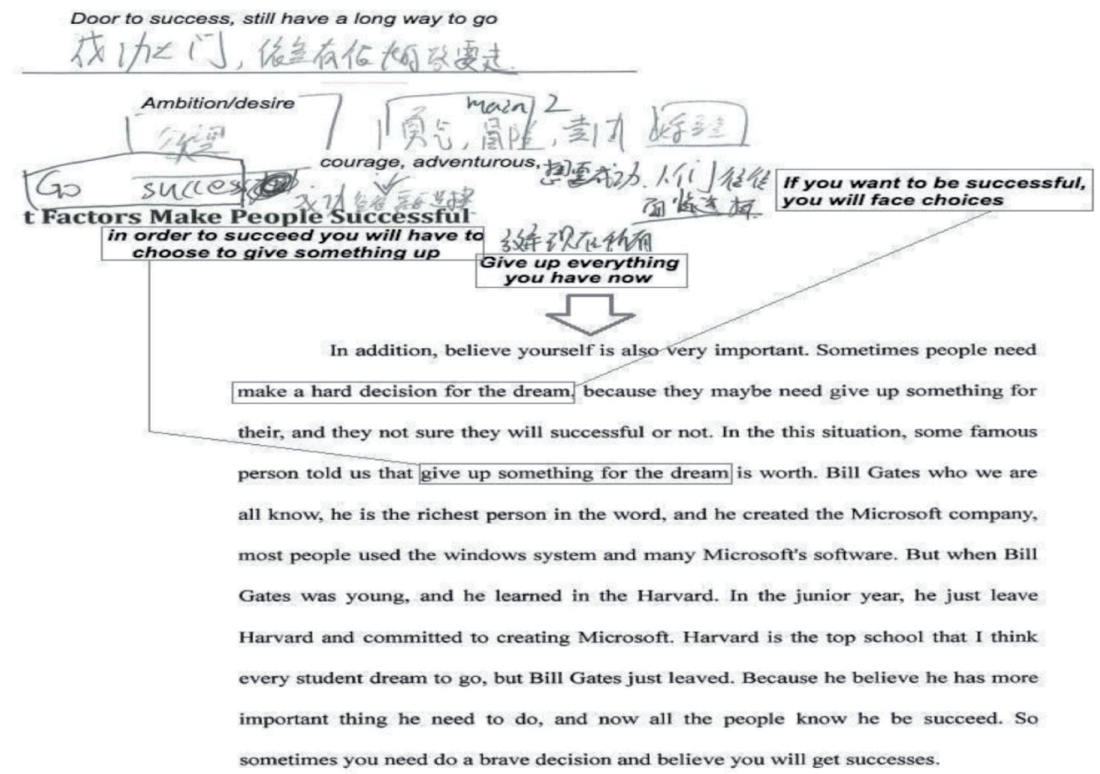

Figure 1. Brainstorming on draft \#2, featured in final draft

Admittedly, not all of the ideas were included in the final draft, but those that were incorporated have been bolded, outlined and traced to their place in the writing. By incorporating Gail's comments, Aaron tried to adopt an academic written identity, which marked a deliberate attempt to appropriate the conventionalized norm of an academic essay in order to win her approval. According to Jaffe (2009: 11), "every performance is recognized as the performer's 'take' or stance on a particular ... genre ... [and] the audience is implicated". In underscoring the evaluator's role, Jaffe calls our attention to the evaluative and gatekeeping role Gail had as his reading audience.

Also important to note, however, is Aaron's approach which followed a slightly different path from that proposed by Gail: he started by producing a draft, went back and created an outline in response to the instructor feedback, and was able to add a new paragraph to complete his final submission, further illustrating his reflexive use of language. The fact that he was able to produce a well-written paragraph in one proverbial shot for the final draft suggests that he is able to (a) write 
at a higher level than the level of instruction, and (b) use Chinese as a translanguaging resource ( $\mathrm{Li} \&$ Zhu 2013) to communicate his ideas in writing. Aaron's 'divergent' approach thus lends support to Casanave's (2012) call for instructors to allow students to take a more flexible agentive approach to process writing by discovering their own process, while taking into account the structural, genred expectations with which they would need to comply.

Remarkably, Aaron was able to incorporate all of the feedback he received from Gail into his second draft. The feedback primarily addressed issues of length and adding more detail. For example, his concluding paragraph was initially only one sentence long, and following the feedback to add to this section, he developed a well-rounded concluding paragraph. That this paragraph begins with the discourse marker 'finally' further suggests that Aaron was trying to apply the discourse associated with academic writing in his revised paper.

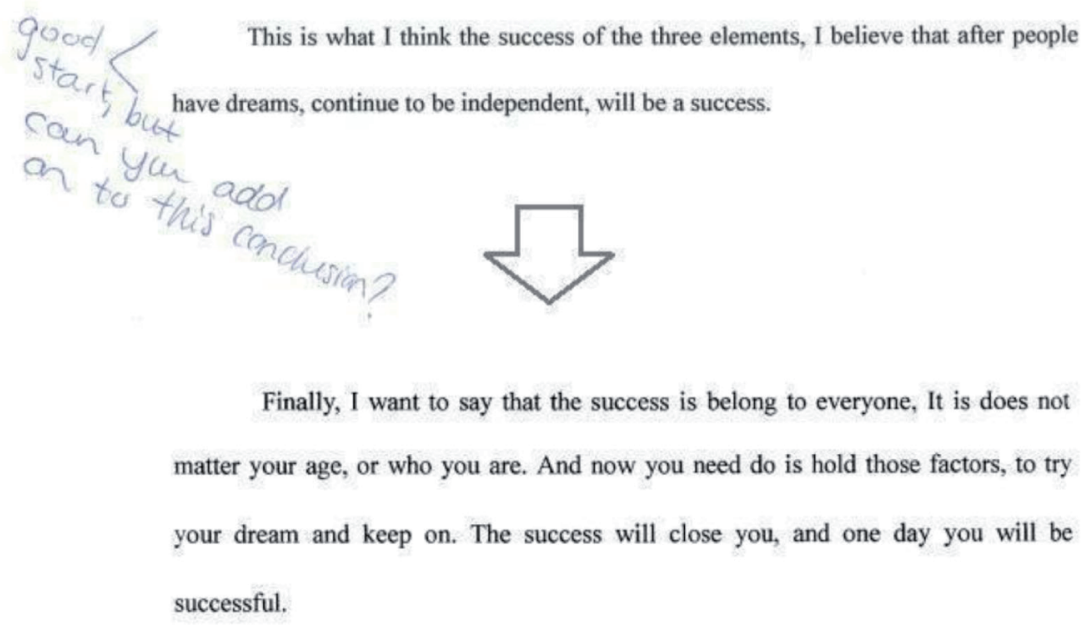

Figure 2. Revisions based on instructor's suggestions

Rather than viewing Gail's suggestions as a top-down enterprise, we argue that Aaron was able to reflexively adapt and adopt the dialogic feedback from her to revise his writing in ways that were aligned with the writing expectations of the ELI. In so doing, he attempted to index the identity of a successful ESL student. For example, in Figure 2, he listed three elements for success and later anaphorically referred to 'those factors' that he identified earlier. His attempt to adopt a personal voice as evidenced in the use of the personal pronoun 'I' (e.g., I think, I believe, I want to say) and second pronoun 'you' (e.g., who you are, will close you, you will be successful) further indicates a marked effort to strike an interpersonal tone with his audience. In short, while credit needs to be given to Aaron who 
creatively sought to challenge the protocol in his ESL writing class, it needs to be noted that such attempts to manipulate the system came at a price in that Aaron did encounter grading penalties as seen in Extract 5. Such punitive measures may be interpreted as a failure to acknowledge his translanguaging skills (Figure 1) and thus constitutes a misrecognition of his cultural capital (Bourdieu 1991). In short, Aaron's affluence, transnational habitus and its attendant capital bore little currency in the linguistic market of his ESL classroom. More importantly, there were other forces at play (e.g., his overall lack of investment in learning English and his local university community) that seemed to block his access to recognized cultural capital and thwart his attempts to positively shape his academic future.

\section{Fractured reflexives}

"All fractured subjects," as observed by Archer (2007:251), "are primarily expressive, wounded and regretful, without being able to design a course of action to ameliorate their situation". In this section, we explore how in spite of his ostensibly detached stance on learning English and interacting with domestic U.S. students, there was a deeply expressive aspect to Aaron that manifested itself in his WeChat exchanges. However, before examining the social media data, we underline how failure to establish an academic and social presence at GLU caused Aaron to retreat into a happier past that to some effect seemed like the only source of happiness to him. As noted, Aaron remained close to the Pittsburgh friends who had relocated to the east (New York) and west (San Francisco) coasts.

In the three extracts that follow, Magda establishes with Aaron that he still maintained a close connection with his high school friends (Extract 6).

Extract 6. Close ties with Pittsburgh friends

Magda: And who are these people?

Aaron: They are all my friends in the Pitt.

Magda: So they all still live in Pittsburgh?

Aaron: No.

Magda: But you all met in Pitt?

Aaron: Yeah.

Madga: So those are high school friends?

Aaron: Yeah, high school.

Magda: So it seems like you have a really strong connection with your high school friends.

Aaron: : Yeah.

(Interview 3, December 4, 2014) 
What is striking about this excerpt is how his former high school, a disembodied institution, continues to be a social nexus for Aaron and his friends even after they have left Pittsburgh. In keeping with the notion of transnational habitus, their continuing friendship underscores how globally mobile individuals like them are able to preserve social ties even though they no longer share a rooted and common physical space (their Pittsburgh high school).

Figure 3, which is from Aaron's WeChat account, exemplifies how the bonds described in Extract 6 were instantiated through regular meetings that took place during school breaks.

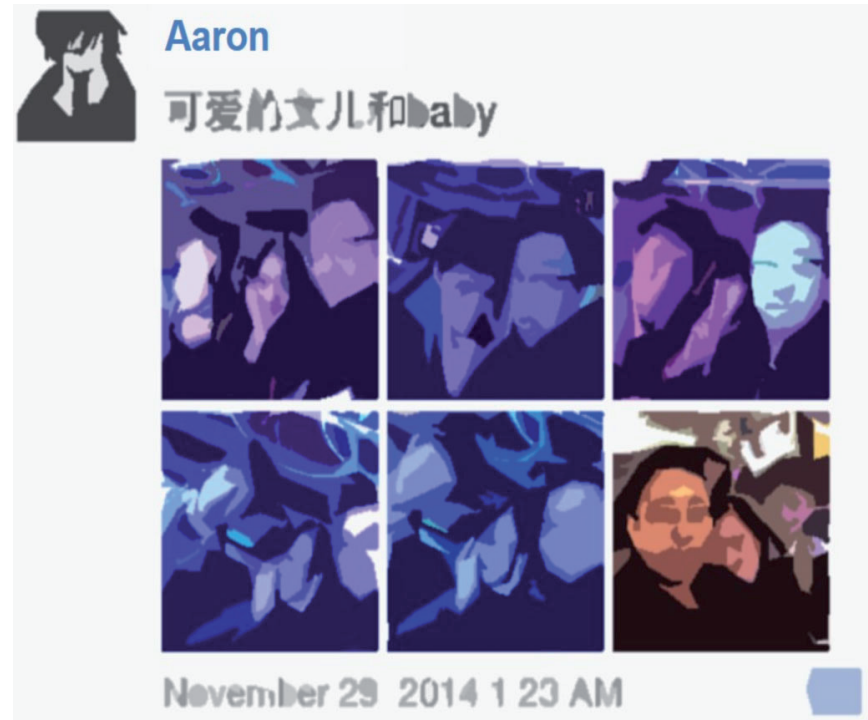

Figure 3. Hanging out with the Pittsburgh gang

Translation: Cute daughter and baby

Titled, "Hanging out with the Pittsburgh gang," Figure 3 depicts smiling faces of Aaron and his friends and encapsulates their intimacy. Such intimacy is reinforced by Aaron's caption, which translates to "Cute daughter and baby" to describe his best friend, Erik, and Erik's girlfriend. That Aaron uses such an endearing term 'baby' to refer to Erik and refers to Erik's girlfriend as 'cute daughter' underlines his close rapport with the two of them. In addition, the physical proximity shared by all three individuals within the various photograph frames resembles the close intimacy often expressed in selfies today. In short, this set of photographs displays a level of friendship that Aaron found lacking in his new university environment at GLU, which is examined next. 
Building on observations made in the two preceding excerpts, Yaqiong in Extract 7 probes Aaron about his state of friendships at GLU, only to find out that he had few local friends and longed to be reunited with Erik, who was in San Francisco.

\section{Extract 7. No friends at GLU}

Yaqiong: Do you think you're happy or unhappy?

Aaron: Unhappy, very sad.

Yaqiong: Just because of ELI courses?

Aaron: $\quad$ No friends. California ... I should go to the University of SF [San Francisco] with my best friend Erik.

Yaqiong: So do you think he will help you find more friends? Or you're just good enough with him?

Aaron: $\quad$ Maybe it's better there, cuz.

Yaqiong: At least you have one friend. Is Erik happy in his university?

Aaron: Happy than me, but not happy. $\quad$ (Interview 3, December 4, 2014)

As disclosed by Aaron, any unhappiness that may have arisen from his ESL course was overshadowed by his being apart from his Chinese high school friends. Thus, his identity as a social actor connected to a network of transnational friends overshadowed his academic identity as an ESL student. Also weighing on Aaron was his unhappiness, which appears to be situated within a hierarchy of unhappiness. On this hierarchy, Erik occupies a lower position than Aaron; the former may be unhappy but in comparison to the latter, Erik is deemed to be happier. Thus, in keeping with the notion of communicative reflexivity (Archer 2007) discussed earlier, happiness takes on a discursive dimension as it is first brought up in the interview conversation by Yaqiong before resulting in a course of action, which in this context is the relational construction of happiness that is framed vis-à-vis Erik's perceived unhappiness. Extract 7 also illustrates how emotions are inextricably linked to one's identity - a phenomenon that is increasingly examined in identity research (e.g., De Costa 2015, 2016; McElhinny 2010). To some effect, these emotions were brought to light because of an inspired confidence in Yaqiong by Aaron, given that they were both Chinese nationals and thus shared a common cultural heritage. By articulating his unhappiness, Aaron solidified his identity as an isolated Chinese international student within his local social context.

As seen in Extract 7, despite his material wealth, Aaron seemed to be impoverished when it came to social relationships. This impoverished state was brought to bear in a WeChat post, where Aaron reposted James Blunt's song, "Give me some love" and added a personal comment: "Why don't you give me some love". 


\section{Why don't you give me some love

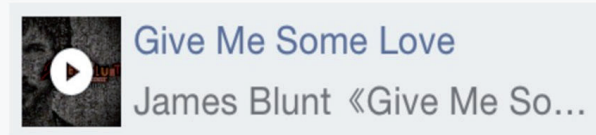

September 21, 2014 10:45 PM

Figure 4. Give me some love

Underscoring the agency of digital natives but emphasizing the affective dimensions of online communication, Ortner (2015:318) notes:

[I]n face-to-face communication we fear to be judged negatively when we display emotion, but in CMC [computer-mediated communication] this fear is not as present, further promoted by the better temporal control over emotion before communicating it. The source of impression formation is all the information a user divulges to others ... but the fact that users can manage their self-presentation gives them more sophisticated strategies to leave an idealized impression.

In Aaron's case, WeChat served as buffer and spared him the possibility of being judged negatively his peers. This social insulation was also made possible by a profile icon that was not an actual photograph of himself but an image inspired by a Japanese anime character. A third degree of separation was realized through Aaron's piggy backing on James Blunt's song. Rather than overtly and directly disclose his need for love, Aaron covertly and indirectly worked in his desire to be loved through a reposting of the song and an appended personal comment that reframed Blunt's imperative "Give me some love" into a more face-saving interrogative request "Why don't you give me some love". Collectively, through adopting the relatively sophisticated strategies of icon use and reposting afforded by WeChat, Aaron attempted to cushion the impact of his desperation and curate an idealized impression of a person in need but not demanding love.

That Aaron was engaged in multimodal semiotic work and communicated his emotions through CMC (Ortner 2015) was further demonstrated through his emoticon-inflected WeChat posts. For example, in Figure 5 he noted, "Am I revenged for my misbehavior [sweating emoticon], shit I can't turn on my computer now ["sad" written in English]" (translation).

Through translanguaging and using emoticons, Aaron was able to mobilize his semiotic resources to communicate his sadness. According to Hanks (1987:670), "The conventions of genre help define the possibilities of meaning in discourse". In Aaron's case, in spite of their brevity, his WeChat messages - as mediated through 


\section{3 \\ 干坏事就会有报应吗 我尼玛现在电脑 打不开了 sad}

November 18, 2014 12:34 PM

Figure 5. Sweating and sad

his use of translanguaging and emoticons - were able to communicate his sadness with amazing specificity and economy.

Furthermore, that Aaron was able to re-post a song (Figure 4) to express his unhappiness strongly suggests his agency, which was moderated in relation to his social circumstances. What Aaron lacked, however, was complete control over how his attempts at impression management were interpreted. As Blommaert (2015) reminds us, meaning is not linear but can yield several different effects. In a similar vein, Aaron did not have control over the types of comments that were generated in response to the information he supplied (Jones \& Hafner 2012). Specifically, despite expressing his desire for love (Figure 4), his September 2014 post got few replies, causing him to follow up with another call for love in November 2014 (Figure 6).

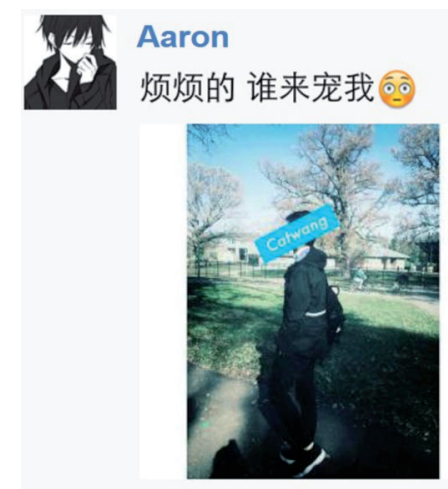

November 3, 2014 12:36 PM

Figure 6. Who'll come to love me?

Translation: Feeling bothered. Who'll come to love me (a shy face).

Here Aaron appears to be reaching out for love and uses a shy face emoticon, which may express an emotion that he chooses not to express with words: this emotion is one of apparent loneliness that he is unable to overcome, so he is hoping that 
someone will initiate a welcoming gesture. Again, as in Figure 6, Aaron framed his post in the form of a question "Who'll come to love me?", and not as a declarative statement, as he invites his virtual audience to engage with him. According to Ortner (2015), connected online users often engage in conscious management of the emotional intensity expressed. Ortner $(2015: 313)$ goes on to add that:

One way to achieve positive judgments, popularity and stronger bonds to one's friends is self-disclosure in profile messages, posted items and private messages usually by using features of oralized written text.

In Aaron's case, his attempts to increase his popularity and forge stronger bonds through self-disclosure did not achieve their desired effects. In other words, an examination of his networked interactional history revealed that the intended uptake that he had hoped for did not materialize.

Effects of fractured reflexives: Denial and resignation

Thus far, we have demonstrated how Aaron used social media in the form of WeChat posts to communicate his loneliness and longing for love. Writing about emotional distress in relation to fractured reflexives, Flam (2010) maintained that such reflexives are often characterized by inner dialogues that go round in inconclusive circles, which increase the subjects' disorientation. While Aaron did not suffer from any disorientation, he did, however, lapse into inconclusive circles and found himself in somewhat inert situations. For example, at the end of the fall semester, he claimed he would study for the TOEFL test over the winter holiday, but did not do anything afterwards to translate this declaration into any form of action.

Rather than detecting any distress on his part, what we discovered over time was an emergent sense of numbness and disengagement. If Aaron was disappointed, he did not now show it, and instead put up an unperturbed façade, as seen in Figure 7.

As seen in the figure, Aaron strikes a laid back pose by leaning against a table with one leg thrust forward and the another arched for balance as he checks his mobile phone. His overall comportment and attire in the above photograph - a manifestation of his bodily hexis (Bourdieu 1984) - suggest a casual attitude generally associated with someone of affluence who is seemingly unruffled in the face of adversity. This view is instantiated by Aaron's own acknowledgment that he would still pose naturally for pictures, even if he failed his tests. One could argue that his sense of composure and arguably defiance might stem from his transnational habitus. More importantly, however, Aaron seemed to slide into a sense of denial, electing to convey a sentiment that everything was fine, as illustrated in Figure 8 and Extract 8. 


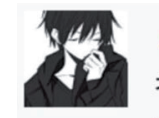

\section{Aaron}

考试不及格 也始终要自然的摆拍

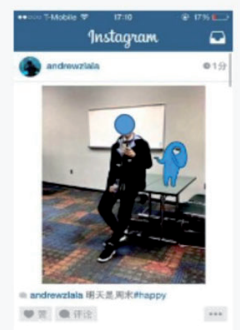

A $\$$ 이

November 7, 2014 5:11 PM

Figure 7. Keep on posing

Translation: Even if I failed my tests, I would still pose naturally for photos as always

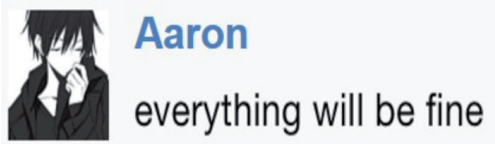

December 27, 2014 9:20 AM

Figure 8. Everything will be fine

Extract 8. Everything is okay

Magda: So, when will you study for the TOEFL test, then?

Aaron: I don't know. I don't know if I make plan. Because plan always change. I don't make plan.

Magda: I guess the first thing is that you need to see if you pass your ELI classes or not.

Aaron: Actually, it's okay. Everything is okay.

Magda: Everything is okay?

Aaron: I don't know how to say but just make me happy. The sad things.

(Interview 3, December 4, 2014)

Particularly notable about Extract 8 is Aaron's uncertainty, first over when he will take his TOEFL test as conveyed through his repeated assertion "I don't know", and later when asked upfront if everything was okay. However, when pressed by Magda, he concedes somewhat ambivalently that he also has to encounter some "sad things". 
In fact, reviewing Figures 7-8 and Extract 8 made clearer to us that things were not going well academically for Aaron in spite of stop-gap measures taken by him (e.g., Figures 1 and 2). If anything, his expression of unhappiness (Extract 7 and Figures 4, 5 and 6) undermine his claims that everything was fine. While Figure 7, which came from data collected in November, hints at possible failure in tests, Extract 8 which took place almost a month later at the end of the fall semester points to how things were not turning out as planned. Extract 9 not only confirms that Aaron did not pass his ESL class, but at this stage, he appears to be resigned to his academic fate, explaining that he had to "accept" his failure and that there was nothing he could to "change it."

Extract 9. Failing all three ESL classes

Magda: Okay. So what will happen if you fail?

Aaron: I need to do the class again. Every class.

Magda: All three [classes]?

Aaron: But when we talked about it I was so sad about this news. But now I accept.

Because I cannot change it.

Magda: True. That's really difficult.

Aaron: No. Because I cannot change it.

(Interview 3, December 4, 2014)

In sum, while disturbing, Aaron's flunking out of ESL did not come as a complete surprise.

\section{Discussion and conclusion}

“Computer-mediated communication (CMC) systems," Walther (2011:443) contends, "in a variety of forms, have become integral of the initiation, development, and maintenance of interpersonal relationships". In this paper, we explored how Aaron attempted to maintain relationships with distal friends who lived outside of the American Midwest. Of interest to us was the ways in which he attempted to maintain interpersonal relationships both online and offline, and the impact these endeavors had on his broader academic socialization and his English language learning. Using the notions of reflexivity and habitus as a heuristic to guide our ethnographically informed examination and combining our analyses with the embodied construct of emotion, we chose to focus on his discursive practices. Our findings revealed that Aaron's disengagement with his studies at GLU was inextricably linked with his social disconnection with the local community.

In addition to contributing to the body of language socialization research on Chinese international students (e.g., Ranta \& Meckelborg 2013), our study calls into question the myth that affluence brings happiness, more specifically 
that affluent international students have an easy time while studying abroad. As Aaron's experiences showed, the English he brought with him to GLU was not ratified, resulting in a sojourn at GLU that was not as rosy as commonly predicted. On a broader level, we demonstrated that economic capital does not always bring with it easy access to social networks. Our data also allowed us to problematize the notion that English language learners are invested in the acquisition of English because it opens up employment opportunities. From Aaron's perspective, English did not seem to play a central role in his future career in finance. In other words, from his perspective, English lacked the symbolic capital that is often associated with it.

Relatedly, and even if Aaron actively sought such capital, it was denied to him because the capital that he brought to the U.S. university was not legitimated, as evidenced by the evaluation of his English skills by his ESL instructor, Gail. In illustrating the capital misrecognition that Aaron encountered, the findings of this study also reveal the dark side of being an affluent international student, the side that excludes individuals whose capital fails to be validated.

On a conceptual level, and in keeping with recent calls by Kramsch (2015) and McNamara (2015) to (re)engage with discussions of language in the humanities, we chose to consider the locatedness of language and how it inevitably folds into the rich histories, cultures, places, and ideologies in which speakers are embedded. Specifically, we examined how Aaron's own trajectory and his multiple acts of reflexivity may have complicated and contributed to his academic experience at GLU. For example, high school friendships that were formed during his time in Pittsburgh continued to shape his interactions at GLU because he was less committed to developing new friendships at his new academic institution.

On a methodological level, our research took us into the digital realm of WeChat, which in turn illuminated and complemented our understanding of Aaron's reflexivity and habitus negotiation. Regardless of context - digital or physical - one thing became increasingly clear following the analysis of our data. To succeed, Aaron needed to become more invested in his learning. At the same time, he was not unaware of his predicament: Aaron knew he needed to pass the English proficiency test at GLU in order to matriculate as a full time student first before he could initiate a university transfer in order to be with his friends on the coasts. In that respect, he had demonstrated some degree of communicative and meta-reflexivity (he knew what obstacles stood in his way). From a metapragmatic perspective, Aaron attempted to mobilize his semiotic resources through three primary communicative genres - his interviews with us, the academic work he produced for his ESL instructor, and the WeChat messages shared with online friends. What he was saddled with, however, was fractured reflexivity because he found himself unable to break free from a set of circumstances that included 
the external academic demands placed upon him (meeting the proficiency requirements set by the ELI), the lack of affective support from family and friends, and a situation where his cultural capital was misrecognized. In the end, it was a combination of emotional and academic disappointments - both of which were mutually constitutive - that led to his sense of resignation.

Writing about the importance of initial successes and learning to be a confident proactive agent on behalf of one's own learning, Norton (2013) underscores the need to create positions of power so that learners align their effective abilities with affordances so that they can succeed academically. On a pedagogical level, one way to initiate the creation of successful platforms for learners like Aaron is to have ESL instructors reframe international students as cosmopolitan intellectuals (Campano \& Ghiso 2011, De Costa 2014) by recognizing the cultural resources they bring within them to the classroom. In addition, teachers need to design opportunities to allow international students to use social media to facilitate language development while also cultivating strong emotional ties with others. At a school like GLU, efforts can be made to partner international students like Aaron with domestic students who may also use the same social media such as WeChat. The latter would probably include students who are interested in learning Chinese and pursuing a career in China. Their investment in working with international students like Aaron would not only provide him with valuable ties to the local community but also much needed emotional support and opportunities to use the target language (in this case English). In this respect, both domestic and international students will have opportunities to engage in constructive translingual (Canagarajah 2013) and intercultural (Clark \& Dervin 2014) exchanges. It is only through the creation of such affordances can we hope to realize a broader applied linguistics agenda of addressing language-related real world problems surrounding the growing number of international students like Aaron.

\section{References}

Adams, M. 2006. Hybridizing habitus and reflexivity. Sociology 40 (3): 511-528. doi: $10.1177 / 003803850663672$

Agha, A. 2007. Language and Social Relations. Cambridge: CUP.

Anderson, B. 1983. Imagined Communities: Reflections on the Origin and Spread of Nationalism. London: Verso.

Archer, M. S. 2007. Making our Way through the World: Human Reflexivity and Social Mobility. Cambridge: CUP. doi:10.1017/CBO9780511618932

Archer, M. 2012. The Reflexive Imperative in Late Modernity. Cambridge: CUP. doi: $10.1017 /$ CBO9781139108058

Block, D. 2015. Social class in applied linguistics. Annual Review of Applied Linguistics 35: 1-19. doi:10.1017/S0267190514000221 
Blommaert, J. 2005. Discourse. Cambridge: CUP.

Blommaert, J. 2015. Meaning as a nonlinear effect: The birth of cool. AILA Review 28: 7-27. doi:10.1075/aila.28.01blo

Bourdieu, P. 1984. Distinction: A Social Critique of the Judgment of Taste. London: Routledge. Bourdieu, P. 1991. Language and Symbolic Power, G. Raymond \& M. Adamson (trans.). Cambridge MA: Harvard University Press.

Campano, G. \& Ghiso, M.P. 2011. Immigrant students as cosmopolitan intellectuals. In Handbook of Research on Children's and Young Adult Literature, S. A. Wolf, K. Coats, P. Enciso \& C. A. Jenkins (eds), 164-176. New York NY: Routledge.

Canagarajah, S. 2013. Translingual Practice: Global Englishes and Cosmopolitan Relations. New York NY: Routledge.

Casanave, C. P. 2012. Controversy and change in how we view L2 writing in international contexts. In L. Alsagoff, S. L. McKay, G.Hu \& W. Renandya (Eds.), Principles and practices for teaching English as an international language (pp. 282-298). London: Routledge.

Clark, J. B. \& Dervin, F. 2014. Reflexivity in Language and Intercultural Education: Rethinking Multilingualism and Interculturality. New York: Routledge.

Darvin, R. \& Norton, B. 2015. Identity and a model of investment in applied linguistics. Annual Review of Applied Linguistics 35: 36-56. doi:10.1017/S0267190514000191

De Costa, P. I. 2010. From refugee to transformer: A Bourdieusian take on a Hmong learner's trajectory. TESOL Quarterly 44: 517-541. doi:10.5054/tq.2010.226856

De Costa, P. I. 2014. Cosmopolitanism and English as a lingua franca: Learning English in a Singapore school. Research in the Teaching of English 49: 9-30.

De Costa, P. I. 2015. Re-envisioning language anxiety in the globalized classroom through a social imaginary lens. Language Learning 65 (3): 504-532. doi:10.1111/lang.12121

De Costa, P. I. 2016. Scaling emotions and identification: Insights from a scholarship student. Linguistics and Education 34: 22-32. doi:10.1016/j.linged.2015.08.004

Duff, P. 2015. Transnationalism, multilingualism, and identity. Annual Review of Applied Linguistics 35: 57-80. doi:10.1017/S026719051400018X

Flam, H. 2010. Emotion, and the silenced and short-circuited self. In Conversations about Reflexivity, M.S. Archer (ed.), 187-205. London: Routledge.

Garcia, O. \& Li, W. 2014. Translanguaging: Language, Bilingualism and Education. Houndmills: Palgrave MacMillan.

Geertz, C. 1973. The Interpretation of Cultures: Selected Essays. New York NY: Basic Books.

Hanks, W. 1987. Discourse genres in a theory of practice. American Ethnologist 14 (4): 668-692. doi:10.1525/ae.1987.14.4.02a00050

Jaffe, A. 2009. Introduction: The sociolinguistics of stance. In Stance: Sociolinguistic Perspectives, A. Jaffe (ed.), 3-28. Oxford: OUP. doi:10.1093/acprof:oso/9780195331646.001.0001

Kelly, P. \& Lusis, T. 2006. Migration and the transnational habitus: Evidence from Canada and the Philippines. Environment and Planning 38 (5): 831-847. doi: 10.1068/a37214

Kramsch, C. 2015. Applied linguistics: A theory of the practice. Applied Linguistics 36 (4): 454-465. doi:10.1093/applin/amv039

Jones, R. H. \& Hafner, C. A. 2012. Understanding Digital Literacies: A Practical Introduction. New York NY: Routledge.

Li, W. \& Zhu, H. 2013. Translanguaging identities and ideologies: Creating transnational space through flexible multilingual practices amongst Chinese university students in the UK. Applied Linguistics 34 (5): 516-535. doi:10.1093/applin/amto22 
McElhinny, B. S. 2010. The audacity of affect: Gender, race and history in linguistic accounts of legitimacy and belonging. Annual Review of Anthropology 39: 309-328. doi:10.1146/annurev-anthro-091908-164358

McNamara, T. 2015. Applied linguistics: The challenge of theory. Applied Linguistics 36 (4): 466-477. doi:10.1093/applin/amv042

Myles, J. \& Cheng, L. 2003. The social and cultural life of non-native English speaking international graduate students at a Canadian university. Journal of English for Academic Purposes 2 (3): 247-263. doi: 10.1016/S1475-1585(03)00028-6

Nedelcu, M. 2012. Migrants' new transnational habitus: Rethinking migration through a cosmopolitan lens in the digital age. Journal of Ethnic and Migration Studies 38 (9): 1339-1356 doi: $10.1080 / 1369183 X .2012 .698203$

Norton, B. 2013. Identity and Language Learning: Extending the Conversation. Bristol: Multilingual Matters.

Ortner, H. 2015. Mediated emotions: Emotivity in the age of information and communication technologies. In Emotion in Language: Theory, Research, Application [Consciousness \& Emotion Book Series 10], U.M. Lüdtke (ed.), 305-324. Amsterdam: John Benjamins. doi:10.1075/ceb.10.16ort

Pérez-Milans M. 2016. Reflexivity and social change in applied linguistics. In Reflexivity in Late Modernity: Accounts from Linguistic Ethnographies of Youth. AILA Review 29 (1).

Ranta, L. \& Meckelborg, A. 2013. How much exposure to English do international graduate students really get? Measuring language use in a naturalistic setting. Canadian Modern Language Review 69: 1-33. doi:10.3138/cmlr.987

Sarangi, S. \& Candlin, C. 2003. Trading between reflexivity and relevance: New challenges for applied linguistics. Applied Linguistics 24 (3): 271-285. doi:10.1093/applin/24.3.271

Sayer, A. 2010. Reflexivity and the habitus. In Conversations about Reflexivity, M. S. Archer (ed.), 108-122. London: Routledge.

Talmy, S. 2010. Qualitative interviews in applied linguistics: From research instrument to social practice. Annual Review of Applied Linguistics 30: 128-148. doi:10.1017/S0267190510000085

Vandrick, S. 2011. Students of the new global elite. TESOL Quarterly 45 (1): 160-169. doi: $10.5054 /$ tq.2011.244020

Walther, J. B. 2011. Theories of computer-mediated communication and interpersonal relations. In The Sage Handbook of Interpersonal Communication, M. L. Knapp \& J. A. Daly (eds), 443-479. Thousand Oaks CA: Sage. 